\title{
El teatro de Jesús Campos o el falso dilema entre tradición y vanguardia
}

\section{The Theatre of Jesús Campos or the False Dilemma between Tradition and Avant-Garde}

\author{
Berta Muñoz Cáliz \\ Centro de Documentación Teatral \\ Universidad Autónoma de Madrid
}

\section{RESUMEN}

En el marco de la posmodernidad artística, y tomando como referencia el movimiento de la transvanguardia en Italia, con cuyos presupuestos encontramos claras similitudes, el teatro de Jesús Campos, situado por la crítica dentro del movimiento llamado «Nuevo Teatro Español», debido a su audacia expresiva y a su compromiso antifranquista, se distingue no obstante de la mayoría de los autores de este grupo en que, lejos de rechazar frontalmente el realismo de los años 50 y 60 , ni la tradición de la comedia y el sainete frecuentadas por los autores conservadores del momento, Campos, ya desde sus inicios a comienzos de los 70 , emplea unas y otras formas como recursos expresivos, desde el convencimiento de que las vanguardias no son sino un eslabón más de la tradición. El análisis de estos aspectos pone en cuestión la periodización que viene usando de forma habitual la historiografía del teatro español más reciente.

Palabras Clave: Jesús Campos; Nuevo Teatro Español; posmodernidad; tradición; vanguardia; transvanguardia.

\begin{abstract}
In the framework of the artistic postmodernism, and with reference to the movement of the trans-avant-garde in Italy, whose ideology we find clear similarities, the theatre of Jesús Campos, located by critics within the movement called «Nuevo Teatro Español», due to their expressive boldness and its commitment to anti-Franco, however differs from most of the authors. Thus, unlike these playwrights, Campos does not reject frontally the realism of 50 and 60 , or the tradition of comedy and the sainete frequented by conservative authors of the time. On the contrary, since its inception in the early 1970s, Campos uses both forms as expressive resources, from the conviction that the avant-gardes are just one more link in tradition. The analysis of these aspects calls into question the periodization that is being commonly used in the most recent Spanish theatre historiography.
\end{abstract}

Key words: Jesús Campos; New Spanish Theatre; postmodernity; tradition; avant-garde; trans-avant-garde. 
A lo largo de su ya extensa trayectoria como dramaturgo, Jesús Campos ha desarrollado una producción «en perpetuo cambio y renovación de formas y contenidos» (Serrano, 2012: 58), caracterizada por «su libertad a la hora de organizar artísticamente, rehuyendo los mimetismos limitadores, los muy diversos contenidos que plantea» (Fernández Insuela, 2012: 22) ${ }^{1}$, tal como han señalado certeramente distintos estudiosos. Esta diversidad formal ha motivado que su teatro resulte difícilmente clasificable dentro de las categorías empleadas habitualmente en los estudios sobre el teatro español contemporáneo; no obstante, como veremos, precisamente esos rasgos que lo alejan de esquematismos prefijados resultan iluminadores a la hora de comprender lo que supuso en la escena española la llegada de la posmodernidad artística y la complejidad de las relaciones entre tradición y vanguardia en el teatro español actual.

Pese a la distancia histórica que nos separa ya del fenómeno al que se denominó como «Nuevo Teatro Español», y pese a tratarse de un término controvertido desde sus comienzos, lo cierto es que aún en nuestros días, a la hora de enfrentarnos al teatro español de las últimas décadas, predomina un esquema historiográfico, sustentado en el método generacional, según el cual este grupo de autores habría rechazado frontalmente los presupuestos estéticos del realismo social de los años 50 y $60-\mathrm{y}$, por supuesto, el de los comediógrafos del teatro comercial del momento- y a su vez a estos autores habrían sido sucedidos por los de la llamada «Generación de los Ochenta», los cuales habrían retomado las formas de la comedia y del realismo y roto a su vez de forma más o menos drástica con la neovanguardia de los 70 . Este esquema basado en rupturas generacionales resulta poco o nada productivo, en nuestra opinión, a la hora de acercarnos al conjunto de la obra de un dramaturgo tan significativo como Jesús Campos, y queda cuestionado en aspectos esenciales a la luz de su producción.

A semejanza de lo que sucede con el esquema generacional, y en estrecha relación con el mismo, también parece necesario poner en cuestión, desde la distancia histórica que nos ofrecen las cuatro décadas ya transcurridas, la periodización que aún hoy se viene manejando según la cual habría un antes y un después del año 1975, nítidamente diferenciados, en la historia del teatro español (así, por ejemplo, Pérez-Rasilla, 2003: 2855-2857). Por el contrario, a semejanza de lo que en los últimos años se viene haciendo desde la

${ }^{1} \mathrm{Al}$ margen de los artículos y ponencias publicados en obras que tratan períodos más amplios, no existe, al día de hoy, un estudio de conjunto que abarque la dramaturgia española del tardofranquismo y el complejo fenómeno de la neovanguardia en los autores españoles. En el ámbito de los grupos independientes, la dirección escénica y la creación colectiva, contamos con un estudio que reivindica este período y lo analiza de forma distinta a como lo había venido haciendo la crítica hasta el momento (Cornago, 2000). No obstante, sigue siendo necesario un estudio equivalente referido a la dramaturgia de aquellos años. 
crítica y la historiografía de otras disciplinas artísticas, parece necesario admitir que, también en el ámbito del arte escénico, la irrupción de la posmodernidad y el inicio en nuestro país de «esta época compleja y contradictoria que aún es la nuestra» (Carrillo, 2011: 75) no surgió de forma inmediata tras la muerte del dictador ni tras la llegada del gobierno socialista, sino que, por el contrario, resulta necesario retrotraer a los últimos años de la dictadura el origen de toda una serie de fenómenos que siguen vigentes en el teatro actual, situando a la dramaturgia española no como una excepción encerrada en su particularismo, sino en el contexto más amplio de un teatro y un arte occidentales que también por entonces viven una etapa de cambios esenciales y de profunda renovación ${ }^{2}$.

En realidad, la dicotomía entre realismo y vanguardia, tan presente en el discurso crítico sobre el teatro español de estos años, se podría situar en el marco de un debate más amplio como es el de las relaciones entre tradición y vanguardia, que si ya desde sus inicios se mostraron más permeables en la práctica artística que en manifiestos y escritos teóricos, a partir de los años 60 , con la irrupción de la posmodernidad artística, se flexibilizarían y permeabilizarían de forma hasta entonces desconocida. A comienzos de los 70, cuando Campos comienza su andadura teatral, revisitar géneros como el sainete, la comedia policíaca o el drama rural, tal como hace este dramaturgo en algunas de sus obras, no formaba parte de ninguno de los discursos dominantes en la cultura teatral del momento. Y su empleo en unos espectáculos que integraban dichos lenguajes tradicionales con técnicas propias de las vanguardias solo puede entenderse, en mi opinión, en el contexto de la posmodernidad artística, con lo que esto implica en cuanto a abandono de la división entre lo alto y lo bajo, apropiación del vocabulario de las vanguardias y su articulación con géneros premodernos y no modernos (Huyssen, 2002: 338).

En efecto, la relación que se establece entre el teatro de Jesús Campos y la tradición va a estar marcada desde sus comienzos por la complejidad, por la ironía, por el juego; por una tensión que tiene su origen en la distancia entre la visión del mundo que expresaban esas formas heredadas y la visión personal del autor. Así mismo, su relación con los lenguajes neovanguardistas propios del momento no es menos compleja, pues aunque, como veremos, existe

${ }^{2}$ En su análisis de los nuevos recorridos de las salas del Reina Sofía dedicadas a lo contemporáneo, Carrillo señala cómo en la presentación de 2009 hubo un cambio esencial con respecto a las colecciones presentadas durante los años anteriores: si anteriormente el inicio del presente se había situado a comienzos de los 80 , con una serie de obras que «proclamaban la definitiva liberación de los viejos fantasmas ideológicos del antifranquismo y se dirigían felizmente hacia un horizonte normalizado en términos de autonomía estética y de mercado» (2011: 52), a partir de dicho año, el último tramo de la exposición permanente se inició con una sala dedicada al arte de principios de los años 70, gesto que, en palabras de este autor, «significaba un giro sustancial respecto a las narraciones previas de la contemporaneidad» (2011: 51). 
en toda su obra un espíritu transgresor propio de las vanguardias («crear es transgredir», afirmará el propio autor en uno de sus primeros artículos, 1974: 18), su vinculación con estos movimientos no se va a limitar a su mera adscripción a uno u otro, sino que va a tomar elementos de varios de ellos y los va a utilizar en función de lo que demande o no la obra en construcción. Esta recurrencia a múltiples fuentes, actuales y del pasado, y la diversidad de formas y estilos a que ello da lugar es lo que sin duda ha desorientado a menudo a la crítica y ha dificultado la ubicación del autor en el panorama del teatro español contemporáneo.

\section{LA VANGUARDia Y EL «NUEVO TEATRO EsPaÑOL»}

Los estudiosos que se han acercado al teatro de Jesús Campos han coincidido en destacar su carácter crítico y experimental y, lo han situado, como se dijo, dentro del llamado «Nuevo Teatro Español», «teatro español underground» o «teatro simbolista» (Oliva, García Templado, Ragué-Arias, Fernández Torres, Serrano, Vilches de Frutos), grupo de autores sumamente heterogéneo cuya sola enumeración (Francisco Nieva, Luis Riaza, Jerónimo López Mozo, Miguel Romero Esteo, Alberto Miralles, Manuel Martínez Mediero o José Ruibal, entre muchos otros) sirve para dar idea de la enorme diversidad textual y escénica a la que se pretendió aglutinar bajo una misma denominación; de hecho, los propios estudiosos no siempre coinciden en incluir los mismos nombres bajo este marbete, dependiendo de los criterios más amplios o más restrictivos que empleen para caracterizarlo. Pese a todo, también las similitudes son destacables y son varios los aspectos en que Campos coincide con ellos, como veremos en este punto.

Así, pese a las evidentes diferencias, todos ellos coincidían en su afán de renovar la escena española con nuevos lenguajes, en muchos casos aprendidos de la vanguardia occidental posterior a la II Guerra Mundial (teatro del absurdo, teatro de la crueldad, happening, etc.), y en su actitud crítica contra la dictadura franquista, lo que trajo consigo que muchas de sus obras fueran prohibidas. Si nos fijamos en las creaciones de Campos, tanto sus textos como sus puestas en escena llevadas a cabo durante aquellos años presentan un fuerte carácter experimental, una indudable audacia expresiva y una alteración de las convenciones de la comunicación habitual entre creadores y público. Así mismo, en todas ellas se evidencia una actitud crítica frente al régimen dictatorial, sea cual sea el tema abordado: desde el matrimonio tal como era entendido por el nacional-catolicismo (Nacimiento, pasión y muerte de... por ejemplo: tú, 1975; En un nicho amueblado, 1974) hasta la pena de muerte (Es mentira, 1980), pasando por la censura (Matrimonio de un autor teatral con la Junta de Censura, 1972) o por la obsesión desarrollista por la productividad (7000 gallinas y un camello, 1976). 
Común igualmente a los «nuevos autores» es la recuperación de un concepto espectacular del hecho teatral (Ruiz Ramón, 1992: 529), que se traduce en una nueva consideración de la importancia de los signos no verbales de la representación, así como en el intento de romper con los límites del espacio escénico convencional (Vilches, 1999: 128-129) ${ }^{3}$. En realidad, el teatro de Campos no solo recupera plenamente este concepto espectacular, sino que este es tal vez uno de los rasgos más característicos y definitorios de toda su producción (Campos, 2014). Como muestra de la importancia que el autor concede a la gestualidad, al movimiento y a los signos no verbales de la representación, valga recordar el baile que él mismo llevaba a cabo en Nacimiento, pasión y muerte de... por ejemplo: tú — «una especie de rock extenuado y patético, que, lejos de ser una expresión secundaria, tomaba el carácter de clímax del drama» (Monleón, 1976b: 33-34)_, o las enormes jaulas con gallinas reales que invadían el escenario del Teatro María Guerrero en 7000 gallinas y un camello (1976), con lo que esto suponía de ruido, de movimiento e incluso de olor, metáfora de un mundo rutinario, esclavizado y maloliente por cuya transformación se abogaba en la obra. Así mismo, la ruptura del espacio escénico convencional está presente en muchos de sus textos, como Matrimonio..., donde el escenario adquiría forma de cámara acorazada convertida en cuarto de estar; En un nicho amueblado (1974), donde los espectadores se veían obligados a huir de una sala inundada por la basura, o, ya en los noventa, en A ciegas (1997), donde actores y técnicos deambulaban entre el público en total oscuridad, con ráfagas de viento y olor a mar como ambientación sensorial. Desde este punto de vista, Campos García no solo coincide con sus compañeros de generación, sino que será uno de los más firmes defensores de la importancia de tales elementos en la puesta en escena de sus obras, llevando hasta sus últimas consecuencias la idea de dirigir sus espectáculos y diseñar sus escenografías para ocuparse de todo un universo de signos no verbales que considera esenciales ${ }^{4}$.

Junto a la recuperación del concepto espectacular del texto, otro de los rasgos que vincularía a Campos con la promoción de «autores simbolistas»

${ }^{3}$ Tal como señala esta autora, «Escribieron textos concebidos para su representación, en los que el soporte lingüístico adquiría su plenitud en relación con los gestos y las variaciones tonales, el movimiento, la música, el juego cromático de los figurines y los efectos luminotécnicos, en la línea de los grandes renovadores de la puesta en escena mundial» (Vilches, 1999: 128-129).

${ }^{4}$ Es más, aunque muchos de los «nuevos autores» tuvieran este concepto espectacular de sus textos, pocos dieron el paso de dirigir ellos mismos o de diseñar escenografías, con las excepciones de Francisco Nieva, cuyos trabajos como escenógrafo son bien conocidos y que ya en democracia dirigiría algún texto propio, y de Alberto Miralles, que por aquellos años dirigió los coros del emblemático espectáculo Marat-Sade, además de dirigir igualmente algún texto propio con su grupo Cátaro. No obstante, será Campos quien lleve adelante con mayor coherencia el proyecto de realizar un «teatro de autor», encargándose no solo de la escritura sino también de la puesta en escena de todas sus obras. 
es el empleo de la alegoría (Ruiz Ramón, 1992: 527 y ss.; Vilches, 1999; Fernández Torres, 1999), modo expresivo que se convertiría en una de las señas de identidad de la neovanguardia española de los años sesenta y setenta. En efecto, Campos lo empleará en muchas de sus obras de aquella época, como en Es mentira (1975), alegoría de las dos Españas inmersas en una guerra fratricida a través de la historia de una mujer encarcelada por su hermana en una cueva ${ }^{5}$, entre otras (Matrimonio de un autor teatral con la Junta de Censura, 7000 gallinas y un camello, En un nicho amueblado, etc.). No obstante, también en este caso nos encontramos ante un modo expresivo que dista mucho de ser exclusivo de una generación ni de un momento histórico determinados, tal como he señalado en otro lugar (Muñoz Cáliz, 2013. Véase igualmente: Cornago, 2006).

Otros factores de carácter histórico y generacional, como el hecho de haber sufrido en gran medida la actuación de la censura franquista ${ }^{6}$, le vincularían igualmente a este grupo de dramaturgos, a los que la dureza con que fueron tratados por el organismo censor les supuso también la denominación de «subterráneos» o underground (Wellwarth, 1972). Así, pues, en la medida en que todos estos creadores procuraron llevar a cabo un teatro renovador en las formas — dimensión espectacular, empleo de la alegoría - y en el discurso - un discurso crítico e implicado, ajeno al teatro evasivo y «digestivo» que ocupaba las carteleras comerciales-, así como en las dificultades que encontraron para salvar los obstáculos que suponían la censura o el propio sistema empresarial del momento ${ }^{7}$, se puede establecer una clara relación entre el teatro de Campos y el citado grupo. Sin embargo, más allá de marbetes generacionales que inciden en la excepcionalidad de la situación española y de sus dramaturgos, lo cierto es que sus creaciones surgen en un momento de eclosión cultural y social, cuyo punto álgido se puede situar en el mayo del 68

\footnotetext{
${ }^{5}$ Aunque la obra admite una indudable lectura política, lo cierto es permite igualmente otras lecturas, tal como señaló Lorenzo López Sancho en su crítica del estreno: «No es fácil la lectura de Es mentira, porque Jesús Campos utiliza varios códigos y hay posibilidades de leer, aprehender la comunicación, en varios y distintos niveles. Es mentira constituye lo que, desde un punto de vista semiótico, podríamos denominar una galaxia expresiva» (López Sancho, 1980).

${ }^{6}$ Tal como analizo en otro lugar (Muñoz Cáliz, 2005), su primera obra presentada ante este organismo, Furor (1971), fue prohibida por unanimidad del Pleno de la Junta de Censura, y en respuesta a esta prohibición el dramaturgo escribió Matrimonio de un autor teatral con la Junta de Censura (Campos, 2004). También sufrió mutilaciones en el texto de su primer estreno: Nacimiento, pasión y muerte de... por ejemplo: tú, en el que hubo de modificar una escena completa, e igualmente se impusieron cortes a otros de sus textos.

${ }^{7}$ Aun así, hubo alguna importante excepción, como fue el propio estreno de 7000 gallinas y un camello en un Teatro Nacional; excepcional no solo en la trayectoria de Campos, sino en el de toda una generación de autores. En 2009 este estreno insólito fue objeto de una importante edición por parte del Centro Andaluz de Teatro, gracias a la cual podemos conocer sus pormenores y su intrahistoria (Campos, 2009).
} 
francés, que supuso para las artes escénicas una profunda renovación, una transformación radical en la manera de entender el teatro y su relación con la sociedad y con la vida cotidiana que tuvo lugar tanto en nuestro país como en el resto de Occidente (Cornago, 2000). Tal como analizaremos a continuación, también hay aspectos esenciales que lo alejan de los citados creadores y que hacen necesaria una revisión de su ubicación en el panorama del teatro contemporáneo.

\section{VANGUARDIA VS. REALISMO}

A semejanza de lo que ocurre con la novela, durante el período de eclosión de las neovanguardias el realismo pasará de ser el lenguaje que se consideraba más apto para reflejar críticamente la realidad social a estar estigmatizado; de ser un lenguaje ética y estéticamente avanzado a considerarse poco menos que periclitado y caduco. Esto es así hasta tal punto que la reacción contra el realismo ha sido considerada por la mayoría de los estudiosos del llamado «Nuevo Teatro» como uno de los pocos rasgos definitorios que cabría aplicar a tan heterogéneo grupo de dramaturgos (Oliva, 1989: 375; Ruiz Ramón, 1975: 529; Fernández Torres, 1999: 30). Así, por ejemplo, Jesús María Barrajón señala que con el término «teatro de vanguardia» referido al teatro español posterior a los años sesenta se suele hacer referencia a todo un colectivo de autores que en aquellos años trataron de dirigirse al público «mediante lenguajes artísticos distintos de los del realismo» (Barrajón, 2003: 2821).

Es este precisamente uno de los aspectos que alejan a Campos con más contundencia del citado grupo de autores. En efecto, frente a quienes por entonces negaban el realismo escénico, al considerarlo un lenguaje heredado de la tradición y opuesto a las corrientes de vanguardia, Campos nunca lo rechazó de plano, y de hecho su obra más conocida de este período, 7000 gallinas y un camello (1976), ha sido calificada por el propio dramaturgo de hiperrealista, calificación que, como veremos a continuación, resulta adecuada en la mayoría de sus situaciones y diálogos.

En la citada obra, ganadora del prestigioso Premio Lope de Vega en 1974 y estrenada en el Teatro María Guerrero dos años después, Campos empleaba las claves del realismo (con los matices que luego veremos) tanto en el lenguaje como en el resto de los elementos espectaculares: la escenografía reproducía con fidelidad una granja avícola, con jaulas, aves e incluso un cauce de agua reales; no menos realista era el vestuario, pues los personajes vestían como gentes del campo en la España de los años sesenta; ni la utilería, compuesta por cubos de metal, escobas, hueveras, sacos de pienso y todo tipo de elementos propios de una granja. También su lenguaje estaba lleno de expresiones coloquiales y presentaba distintos registros según la procedencia social de los personajes. La interpretación que Campos marcó desde la dirección se 
realizó igualmente dentro de los parámetros realistas, tal como se puede comprobar gracias al fonograma grabado por el Centro de Documentación Teatral. Además, la construcción de sus personajes permitía que el público empatizara y se identificara con ellos, en lo que nuevamente se alejaba de las corrientes antirrealistas en boga en los años $70^{8}$. Aunque este realismo escénico se quebraba a través de elementos puntuales - como el director de orquesta volando hacia el peine del teatro o los músicos caracterizados de monstruos de película - y era trascendido por una significación global en clave simbólica, en cualquier caso, elementos como los citados lo alejaban en gran medida de los dramaturgos neovanguardistas de su generación y evidenciaban que su estética llevaba derroteros bien distintos a los de dichos autores.

No obstante, el realismo de Campos no es una mera continuación del realismo social de los años 50 y 60. Pese a las evidentes diferencias que existían entre los distintos dramaturgos de la llamada «generación realista», todos ellos tenían como objetivo la denuncia de las duras condiciones de vida de los perdedores del sistema, evidenciando el contraste entre la realidad reflejada en sus obras y el vacuo triunfalismo del régimen franquista. De algún modo, se puede afirmar que estaban escritas desde la rotundidad de un sistema ideológico que desvelaba los problemas y proponía soluciones; de acuerdo con un momento histórico en el que todavía imperaban las ideologías «duras». Si nos fijamos de nuevo en 7000 gallinas y un camello, en esta obra se nos muestra igualmente un entorno hostil y asfixiante, pero el propio protagonista queda en evidencia con su comportamiento, con su utopía inútil y su salida en falso de la situación. Y si bien tanto en los dramas realistas como en esta obra se aboga por la necesidad de un cambio radical que rompa con la situación reflejada, a diferencia de aquellos, la obra de Campos refleja ante todo un sentimiento de desconcierto, sin que se proponga solución alguna.

En estrecha relación con el punto anterior, y también a diferencia de los dramaturgos del realismo social —así como de los novelistas y poetas sociales de los mismos años-, el dramaturgo jiennense nunca empleó el realismo de forma militante, como único lenguaje apto para la denuncia de la realidad social que se oponía a la frivolidad de la comedia burguesa y del teatro comercial. En su caso, lo emplea como un recurso más para expresarse, y cuando lo necesite recurrirá igualmente a los lenguajes de vanguardia (así, por ejemplo, en Es mentira, 1975; A ciegas, 1995; o El profanador de sepulturas, 1996)

\footnotetext{
${ }^{8}$ Con estos términos se refirió Ruiz Ramón a los personajes del «Nuevo Teatro»: «El personaje dramático es raras veces una persona con soporte en una conciencia individual o un carácter dotado de autonomía, portador de un nombre propio, construido según una coherencia interna que lo sustente como individuo. Es más bien un signo, un puro elemento funcional, la cristalización o el precipitado de un proceso previo de abstracción que hace de él un simple nexo entre situaciones o un mediador del discurso crítico. [...] Podríamos hablar, pues, de la muerte del personaje teatral como persona humana, de la sustitución del personaje-persona por el personaje-signo»(1992: 527).
} 
o incluso a los denostados géneros comerciales, como veremos. Lo cual revela una concepción del teatro y de su función en la sociedad muy distinta a la que venían manejando los autores más comprometidos hasta los años sesenta; lejos de entender el teatro como una herramienta de concienciación social, un instrumento con el cual el dramaturgo ilumina una parcela de la realidad que permanecía oculta para los espectadores, para Campos García la escritura no es una forma de transmitir lo que previamente ya se sabe, sino una herramienta de conocimiento, un instrumento para penetrar en lo desconocido, de forma que el autor es el primer sorprendido por su propia obra (Santolaria, 1994: 235). Finalmente, si en los dramas realistas no había demasiado espacio para el humor ni para la ironía, estos serán, en cambio, dos elementos constantes en prácticamente todo el teatro de Campos.

7000 gallinas y un camello sería tal vez el caso más evidente de empleo del realismo en el teatro de Campos, pero no el único. Si en algún momento de la reciente historia teatral española realismo y vanguardia se percibieron como términos contradictorios y hasta opuestos (con sonoras polémicas incluidas de marcado carácter generacional), lo cierto es que el dramaturgo jiennense en todas sus etapas ha empleado en sus textos un lenguaje realista y coloquial (así, por ejemplo, en Danza de la chatarra, 1982; Danza de los veraneantes, 1982; Patético jinete del rock and roll, 1998; o Naufragar en Internet, 1999), al tiempo que no ha dudado en romper esta convención empleando estrategias propias de la vanguardia escénica cuando la obra así lo exigía.

\section{VANGUARDia VS. TRADición DE TEATRO BURGUÉS}

Es más, Campos no solo acepta como legítimo el lenguaje del realismo y lo incorpora a sus obras cuando lo cree necesario; tal como se apuntó, también incorpora recursos propios del sainete, de la comedia, del género policíaco, del drama rural y, en general, de los géneros más estigmatizados por la intelectualidad teatral del momento y frente a los que se alzaron, en nombre de la vanguardia, la mayoría de los «nuevos autores» de su generación. De algún modo, Campos opta por no limitarse a los lenguajes investidos de mayor prestigio en aquel momento, como podían ser el absurdo, el teatro de la crueldad o el happening, sino que considera como recursos expresivos legítimos una serie de lenguajes desacreditados por su carácter popular o por su anclaje en la tradición y su falta de modernidad.

Ahora bien, al tiempo que emplea lenguajes tradicionales y populares, Campos introduce contenidos críticos ajenos a la visión del mundo que estos solían reflejar. Y al hacerlo, dichos lenguajes quedan modificados de forma sustancial; hasta tal punto que puede decirse que quedan cuestionados, puestos en evidencia, y con ellos, las mentalidades que los generaron. El autor es consciente de esta estrategia que emplea en sus obras y lo es desde el comien- 
zo de su trayectoria en los setenta, tal como se deduce de alguna entrevista realizada por aquellos años (Heras, 1972) ${ }^{9}$. Así, por ejemplo, un texto como En un nicho amueblado, escrito en 1974 (Premio Eulalia Asenjo de la Real Academia Española), mezcla de forma natural elementos del sainete costumbrista y del teatro del absurdo. En ella, la acción se inicia con el anuncio del amortajamiento y posterior entierro de una joven, sin que a la familia parezca preocuparle demasiado, más ocupada en detalles como la preparación del convite o la tardanza de los invitados. Los diálogos se suceden en un tono desenfadado y coloquial, próximo a la comicidad del sainete costumbrista. Finalmente, comprendemos que el entierro de la protagonista no es sino una metáfora de estado de sumisión y de falta de perspectivas vitales que entonces aquejaba a la mujer tras el matrimonio. El empleo de las formas sainetescas, lejos de atenuar lo terrible de la situación, lo refuerza mediante el contraste y apela directamente a la emotividad de un espectador predispuesto a reírse y cuyo horizonte de expectativas irá variando hasta el desconcierto por la imprevista evolución de los acontecimientos ${ }^{10}$.

Igualmente, como vimos, en 7000 gallinas y un camello (1973) confluían una estructura próxima a las parábolas políticas que por entonces estaban escribiendo otros autores del «Nuevo Teatro» y unas situaciones y diálogos propios de un drama rural. En efecto, Campos escoge un género absolutamente

${ }^{9}$ «Matrimonio de un autor teatral con la Junta de Censura es, en la forma, una obra policíaca, con cadáveres, intrigas, intervenciones policiales y demás recursos del género; tiene, o al menos yo he pretendido que tenga, elementos para entretener a un público no especializado. Aparte el envoltorio, la obra ofrece un subtexto muy a flor de piel y basta la clave del título para descifrar el valor simbólico de cada uno de los elementos del drama. [...] Furor es esencialmente una obra bien construida a la manera tradicional, pero dentro de una arquitectura teatral casi mecánica se encierran ideas que irritan, que despiertan furor. [...] $L a$ grieta es una obra totalmente comercial, en el peor sentido de la palabra, que al final del primer acto se desmorona para sorprender en su salsa al espectador burgués al que directamente va dirigida» (Heras, 1972: 8-9).

${ }^{10}$ A modo de ejemplo, reproducimos un fragmento de un diálogo:

José.-[...] He consentido en que la niña muera en la cama porque morir en una excursión, parece ser que no es elegante. Y lo admito, yo de elegancias... Ahora, amortajarla de rosa... Eso... eso es una cursilada.

Abuelita.-Lo será, pero es que es un capricho. Siempre me hizo ilusión tener una nieta vestida de princesa; pero claro, como era tan levantisca, con tal de llevarme la contraria... Porque es que hay que ver cómo se vestía.

Aurelia.-Eso es verdad. Y que Dios la tenga en su Santa Gloria, pero es que la niña era un pendón.

José._Le saldría a la tía.

Aurelia.-Al cabrón de su padre.

Pedro.-Aurelia, no empecéis.

(Toses generales)

Abuelita._- ¿Y sabéis lo que tampoco estaría mal? El hábito del Carmelo. José.-No, por Dios. El vestido rosa»(Campos García, 1997: 24). 
en desuso en la España de los años setenta, como es el drama rural, para hablarnos de labores rutinarias, de expectativas frustradas, de vidas sin horizonte. Si, tal como señaló Mariano de Paco, el drama rural presentaba las pasiones humanas y los conflictos de honra conforme a «una visión idealizada del campo, situando allí un mundo de modelos puros, sentimientos vírgenes y ética rudimentaria» (1971-1972: 141-142), en la obra de Campos el problema de honra apenas queda apuntado, no hay grandes pasiones, solo necesidad de escapar del tedio y la monotonía. Los propios protagonistas no son campesinos, sino que han llegado al campo huyendo de la vida urbana y enseguida se verán decepcionados por su nuevo entorno. También aquí, por tanto, existe un fuerte contraste entre lo previsible en el género y la visión del mundo que se nos presenta, tan alejada del tópico. La desazón que sentimos ante ese microcosmos dedicado únicamente a producir y falto de hálito vital se multiplica gracias a la utilización de un molde genérico del que cabía esperar idealismo bucólico y grandes pasiones. 7000 gallinas y un camello es tal vez el último eslabón de una tradición que se inició en el Siglo de Oro, con los dramas campesinos de honor, y que se cierra con una visión alejada de cualquier tipo de idealismo, escéptica y radicalmente contemporánea. Solo el inesperado viraje que el autor da finalmente a su obra, con los personajes saliendo de escena como si de maniquíes se tratara y con música rock en directo, invitaba a romper con ese mundo mediocre y gris a través de un vigoroso mensaje de esperanza y de cambio.

Se diría, pues, que Campos maneja con gran libertad los recursos que le ofrecen tanto la tradición, con todo un caudal de recursos expresivos estigmatizado por sus compañeros de generación, como las propias vanguardias, que pasan así a ser un eslabón más de la cadena de la tradición.

\section{NO HAY FORMA DE PARTIR DE LA NADA}

En su recuperación del realismo, de la tradición de la comedia, el sainete y otros géneros populares, Campos no solo se desmarcaría de la particular neovanguardia española que constituyó el «Nuevo Teatro». También escapa de la definición de la propia vanguardia, entendida como la negación de la tradición artística occidental y la búsqueda de algo radicalmente nuevo. El propio autor ha comentado en alguna ocasión que «no hay forma de partir de la nada, pues cada obra tiene el todo por ciento de tradición y un apenas nada por ciento de originalidad»(Campos, 2001). Y en otro lugar, expresará su opinión de que no hay otro modo de romper con las convenciones que el de partir de ellas: "Jugamos siempre a partir de unas reglas del juego, y aun en el caso de que el juego consista en negar esas reglas, el referente de las reglas que se niegan es condición obligada para poder negarlas» (Campos, 2003). Así, pues, en el caso de Campos -y en esto participa de una de las princi- 
pales características de la posmodernidad artística-, se produce una recuperación del valor de la técnica, del conocimiento de esa tradición sobre la que se trabaja, y esto se produce en un momento histórico en el que las experiencias vanguardistas de desprecio hacia la técnica y la tradición se han revelado como carentes de sentido, en la medida en que finalmente, tal como señaló Habermas, han acabado siendo legitimadas por aquellas instancias que se proponían desmantelar ${ }^{11}$.

Este acercamiento a las formas del pasado va a suponer, por una parte, una forma muy personal de enfrentarse a la creación, pero, por otra, lo va a vincular a la posmodernidad artística, en la medida en que sus creadores, tanto en el teatro como en la pintura, en la música o en la literatura, y tanto en nuestro país como en el resto de Occidente, han venido recuperando los vínculos con la tradición que las vanguardias quisieron demoler. Al igual que otros creadores posmodernos, Campos no entiende el conjunto de creaciones que le han precedido y las formas de ellas heredadas como algo que hay que desechar por completo para empezar a construir desde cero. Su acercamiento a dichas formas no se basa ni en asimilarlas y continuarlas de forma acrítica, ni en negarlas de forma radical, sino en partir de ellas al tiempo que en cuestionarlas y renovarlas, en jugar — término que el propio Campos emplea a menudo para referirse a su forma de enfrentarse a la creación- con sus recursos expresivos para descubrir nuevos significados, para llegar a lugares insospechados. Y precisamente en este juego con la tradición reside uno de sus rasgos distintivos como creador.

Este proceso de aproximación a la tradición no excluye, como se apuntó, la utilización de elementos vanguardistas. Es más, la presencia de la vanguardia en este teatro no se reduce a la utilización de una serie de recursos formales más o menos audaces, sino que se puede afirmar que la vanguardia, en un sentido distinto al que hasta ahora venimos viendo de este término, está presente en todo su teatro, en la medida en que esta «se rebela contra las funciones normalizadoras de la tradición» (Habermas, 1985: 22) y «se considera como invasora de un territorio desconocido, exponiéndose a los peligros de encuentros súbitos y desconcertantes, y conquistando un futuro todavía no ocupado» (Habermas, 1985: 21). En efecto, la incorporación de elementos del pasado no excluye el que esos elementos sean transgredidos y presentados de forma radicalmente nueva. Se podría afirmar que el modo en que tradición y vanguardia coexisten en este teatro viene dado por un impulso rompedor y anticonvencional que atraviesa unas formas heredadas de la tradición. De al-

\footnotetext{
${ }^{11}$ En palabras del filósofo alemán, «[...] los intentos de declarar que todo es arte y que todo el mundo es artista, retraer todos los criterios e igualar el juicio estético con la expresión de las experiencias subjetivas... todas esas empresas se han revelado como experimentos sin sentido. Estos experimentos han servido para revivir e iluminar con más intensidad precisamente aquellas estructuras del arte que se proponían disolver» (Apud Foster, 1985: 30).
} 
gún modo, nos encontramos ante la necesidad de expresar un profundo desacuerdo con una serie de convenciones y de ideas socialmente admitidas, que se articula sin embargo a través de unos moldes que sí son los aceptados y los reconocibles por la sociedad, los cuales finalmente acaban por descoyuntarse bajo la presión de las ideas rompedoras que subyacen en ellos ${ }^{12}$.

Junto a los casos a los que ya hemos hecho referencia, un claro ejemplo de esta recuperación de un género tradicional y denostado para implosionarlo desde su interior, esta vez referido a su etapa más reciente, lo constituye Triple salto mortal con pirueta (1997): una aparente comedia que, en principio, invita a pensar en una historia de celos e infidelidades entre los personajes de una pareja acomodada, en la línea de la «alta comedia» de los años cincuenta. El hecho de que la acción tenga lugar en un dormitorio absolutamente transparente y lleno de manchas de sangre por todas partes rompe con el esquema convencional del género, que quedará definitivamente alterado cuando los personajes se maten el uno al otro hasta en tres ocasiones para retornar finalmente a la escena inicial. Los propios diálogos, sin prescindir de la elegancia y el ingenio propios del género, dejan ver una relación mucho más amarga, más mordaz y más compleja que la de las idealizadas parejas de las comedias de los años cincuenta.

El hecho de haber seguido un camino personal, al margen de movimientos y tendencias, ha dificultado la labor de la crítica a la hora de situar este teatro en el panorama teatral del momento. Sin embargo, si nos salimos de las categorías que habitualmente se manejan desde la historiografía teatral y nos asomamos al ámbito del arte contemporáneo en el contexto internacional, vemos que Campos, en la época en que comienza a escribir, no estaba solo en su aventura de crear algo nuevo y distinto a partir del diálogo con la tradición.

\section{MÁS ALlÁ DE LA VANGUARDiA}

A mediados de los años 70, el crítico de arte italiano Achille Bonito Oliva acuñó el término de transvanguardia ('más allá de la vanguardia') para referirse a un conjunto de pintores que, por aquellos años, reaccionaron con-

${ }^{12}$ El teatro de Campos es vanguardista en su esencia si, como señala Habermas, «La vanguardia debe encontrar una dirección en un paisaje por el que nadie parece haberse aventurado todavía» (1985: 21). El propio hecho de volver la mirada al pasado teatral y revisarlo desde postulados insólitos en la España del momento, así parece demostrarlo. Por otra parte, actitudes como la de llevar adelante un modelo de autoría de espectáculos insólito en sus comienzos, o la de renunciar a los actores más renombrados cuando estrena en el Teatro Nacional para, en su lugar, llevar a cabo el montaje con una compañía de teatro independiente (Campos, 2009), son suficientemente significativos de esta actitud transgresora y propia de quien se aventura por territorios no transitados. 
tra el arte conceptual regresando a la alegría y a los colores de la pintura. Dicho término hacía alusión a una actitud integradora que, de algún modo, tomaba la historia del arte en su conjunto, tanto la de los períodos clásicos como la de las propias vanguardias, como un cúmulo de recursos expresivos que el creador podía manejar a su antojo. «La transvanguardia abre un amplio abanico de posibilidades que permite que el arte se mueva en todas direcciones, incluidas las del pasado» (Bonito Oliva, 1979: 19; apud Guasch, 2000: 275). Así, la transvanguardia se presentaba «como un recorrido a través de toda la historia del arte, incluyendo las vanguardias e incluso las culturas menores» (Bonito Oliva, 1986: 23; apud Guasch, 2000: 276).

A diferencia de aquellos artistas que pretendían romper completamente con el pasado, los creadores transvanguardistas no trataban de ignorarlo o apartarse de él, sino de recorrerlo, «pero no para imitarlo, sino para cuestionarlo e interpretarlo sesgada y oblicuamente» (Guasch, 2000: 276-277). Lejos de negar las vanguardias, Bonito Oliva afirmaba: «Si llamé a este movimiento transvanguardia es porque atraviesa la vanguardia, no porque la anule» (Navarro, 1989). En otro lugar, el teórico italiano consideraba que la transvanguardia constituía «la única vanguardia posible», en la medida en que permitía al artista conservar su propia tradición junto con otras que podían reanimar su tejido (apud Jiménez, 2010: 123).

De algún modo, la actitud de estos creadores suponía aún una mayor libertad que la de los artistas vanguardistas, al aceptar formas vetadas a aquellos; en palabras de Bonito Oliva, «La transvanguardia trabaja fuera de la tradición única y acepta el principio del eclecticismo, de la contaminación, y todos aquellos procedimientos que permitan una creatividad libre, fuera de la moralina de la vanguardia» (1982). Su actitud sería una «actitud nómada, por lo que ello implica de apertura, pragmatismo y viaje mental, un nomadismo que posibilita recuperar, por medio de la memoria histórica, los estilos de épocas pasadas e incluso los lenguajes que han formado parte de las vanguardias» (Guasch, 2000: 277).

El término acuñado por el teórico italiano para la pintura resulta perfectamente aplicable al trabajo que, en el ámbito del teatro, viene haciendo Campos en nuestro país desde los años setenta. El eclecticismo, la libertad con la que transita por los distintos lenguajes, la mezcla de lo culto y lo popular, de realismo y vanguardia, su cuestionamiento y reinterpretación de la tradición, o su uso de la misma como paleta de recursos son elementos sin los cuales no se entendería su forma de enfrentarse a la creación. Así, por ejemplo, en su prólogo a A ciegas, Cristina Santolaria afirma que en esta obra Campos «ha asimilado diferentes tendencias de la tradición escénica occidental, ha sintetizado estéticas dispares de diversos momentos de la historia teatral» (Santolaria, 1997: 30). Un testimonio más del eclecticismo de su obra serían las palabras de José Monleón a propósito de 7000 gallinas y un camello: 
En realidad, los planteamientos de Jesús Campos son siempre imaginativos y abiertos, combinando, como respectiva expresión de los órdenes aparentemente conflictuados, el lenguaje más rabiosamente naturalista —ante un infierno de gallinas vivas que ocupan el foro- y una serie de elementos estilizados y barrocos, ya sea la música de Vivaldi, ya sean las escalinatas que bordean el espacio de la granja (Monleón, 1976a: 64).

En sus propias declaraciones podemos encontrar una cierta sintonía con este movimiento y con las afirmaciones de su principal teórico. Si en 1982 Bonito Oliva afirmaba que la transvanguardia «acepta todos los procedimientos que le permitan una creatividad libre», años después, sin conocer los planteamientos teóricos del crítico italiano, Campos describiría así lo que supuso para él la asistencia en 1973 al Festival de Nancy en cuanto a reformulación de su forma de trabajar:

Formulando entonces el propósito, aún vigente para mí, de que en lo sucesivo haría todo aquello que me viniera en gana, sin más limitación ni cortapisa que la de dar respuesta a las necesidades de la comunicación, obrando al margen de las modas, utilizando tanto unos códigos como los contrarios, sin más fin ni objetivo que el de conmover, y concediéndome para ello la máxima libertad en el empleo de recursos de todo tipo [...] (Campos García, 2005a).

Y si en las mismas declaraciones Bonito Oliva señalaba que la transvanguardia «supera un experimentalismo histérico e intenta encontrar un equilibrio entre tradición e innovación» (1982), en otro lugar, el propio Campos muestra su parecer acerca de la exaltación de lo nuevo y el rechazo de toda tradición, una actitud que, en su opinión, comenzó siendo vanguardista y ha terminado por obedecer a los dictados de ciertas modas:

La exaltación de la moda — tan útil para el beneficio empresarial— ha generado una mentalidad que estima lo nuevo como un valor en sí, y esto es tan generalmente aceptado que la defensa de lo antiguo, en según qué circunstancias y dependiendo de qué matices, podría considerarse como una actitud revolucionaria (Campos, 2005b).

Además, Campos va a coincidir con los artistas transvanguardistas en su rescate de las formas propias, aprendidas en la rica y fructífera tradición del teatro español. En efecto, frente a la idea globalizante y la hegemonía del arte norteamericano, los artistas italianos reivindicaron «el genius loci, el propio territorio antropológico», en una tentativa de restituir una identidad en el artista, «fuera de la ideología y del darwinismo lingüístico» (Bonito Oliva, 1982). Y tanto en el caso de Campos como en el de los artistas italianos esta reivindicación de lo propio tiene un carácter fundamentalmente emotivo y subjetivo, tan alejado de los nacionalismos del pasado como de la xenofobia que, en nuestro país, habían expresado algunos de los dramaturgos realistas: el artista trabaja con esquemas que ha aprendido durante su infancia; transmite sus vivencias y sus emociones apoyándose en aquellas formas que a él 
mismo le emocionaron y le divirtieron en su día. Junto con el eclecticismo y la mezcla de estilos, el individualismo y la subjetividad son rasgos que aproximan las creaciones de Campos a las de este conjunto de artistas.

Llegados a este punto, se hace necesario volver la mirada a la vinculación personal de Campos con esos géneros infravalorados, con ese teatro comercial y esa tradición negada por la vanguardia. En varias entrevistas el dramaturgo ha comentado la intensa vinculación que durante su infancia mantuvo con la tradición de la comedia y el sainete (Martín, 2002), de los autos sacramentales, de las zarzuelas y Tenorios que se representaban en su Jaén natal, de los títeres de la Tía Norica... La experiencia universitaria en el TEU de Granada y la colaboración con Martín Recuerda le permitirían acceder a la práctica escénica y le crearían un vínculo afectivo que tal vez guarde relación con el hecho de que Campos nunca mostrara desdén alguno hacia los dramaturgos realistas, a diferencia de muchos de sus compañeros de generación. Tal vez esta experiencia personal nos ayude a comprender las razones vitales y emocionales por las que el dramaturgo nunca se desvinculó de esta tradición ni nunca la consideró como algo a rechazar de plano.

Pero su conocimiento del arte escénico no se limitaría a manifestaciones como las anteriormente comentadas. Desde su juventud, Campos sería un ávido espectador de otro tipo de teatro mucho más novedoso. Su asistencia a las funciones de cámara y ensayo que se hacían en el Teatro Beatriz, así como a las representaciones de grupos de teatro independiente que se llevaban a cabo en distintos Colegios Mayores, su lectura de los textos que publican Primer Acto, Taurus o Cuadernos para el Diálogo, y muy especialmente su viaje al Festival Mundial du Théâtre de Nancy (Francia) en 1973 van a abrirle todo un horizonte de formas nuevas y discursos insólitos. Un horizonte que, a su vez, va a determinar su posterior relación con los discursos escénicos del pasado $^{13}$.

Esta multiplicidad de fuentes, de tradiciones y de estilos, unida a una actitud que no descarta de antemano ninguno de ellos, va a resultar esencial a la hora de comprender la obra de este autor. Su teatro, integrador y plural como lo es el arte de la posmodernidad, no parte, pues, de un intento de romper con un arte anterior que se considera caduco, al modo en que sí lo hicieron las vanguardias y en que lo harían muchos de los dramaturgos neovanguardistas; no se trata de negar otras creaciones, sino de expresar las propias

${ }^{13}$ Él mismo ha relatado así la experiencia que supuso su viaje a Nancy y la consiguiente toma de contacto con la vanguardia internacional: $«[\ldots]$ en esas mismas fechas viajamos a Nancy para asistir a su festival [...]. El encuentro con el teatro del mundo fue una experiencia inolvidable; conviene recordar que venía de una práctica teatral adocenada en la que imperaba la comedia burguesa, y en la que el histrionismo era sinónimo de cartón piedra. Enfrentarnos a la organicidad, al riesgo, a la diversidad, en definitiva, a aquel despliegue de compromiso vital y de imaginación, produjo en mí tal impacto que me obligó a replantearme mi concepción del teatro» (Campos, 2005a). 
emociones y las propias vivencias con la máxima eficacia, apropiándose para ello de cuantos recursos expresivos le sirvan para este fin.

\section{TEATRO Y POSMODERNIDAD ARTÍSTICA}

Como hemos visto, el concepto de transvanguardia se adecúa en muchos aspectos al trabajo que Campos viene realizando desde los años setenta. Sin embargo, este no deja de ser un concepto que, pasado el tiempo, ha quedado circunscrito a un grupo de pintores muy concreto. En realidad, muchos de los rasgos señalados por Bonito Oliva como propios de la transvanguardia son extensibles al arte posmoderno en su conjunto y han sido teorizados por muchos otros autores, por lo que intentaremos situar la obra de Campos en el contexto, más amplio, de la posmodernidad artística. Si bien este término se presta a múltiples interpretaciones, y una de las más populares y extendidas estaría ligada a una recuperación de la tradición en todos los órdenes, propia del neoconservadurismo que se dio en Occidente desde los años ochenta, no obstante, tal como señaló Hal Foster, también hay un posmodernismo crítico que asume la herencia del modernismo y se propone seguir avanzando sobre esta herencia: «existe hoy una oposición básica entre un posmodernismo que se propone reconstruir el modernismo y oponerse al status quo, y un posmodernismo que repudia al primero y elogia al segundo: un posmodernismo de resistencia y otro de reacción» (1985: 11). El primero de ellos, que es el que aquí nos interesa y en el que creemos que, por todo lo dicho hasta ahora, debe situarse la creación escénica de Campos, es referido por Foster en los siguientes términos:

[...] un posmodernismo resistente se interesa por una deconstrucción crítica de la tradición, no por un pastiche instrumental de formas pop o pseudohistóricas; una crítica de los orígenes, no un retorno a estos. En una palabra, se trata de cuestionar más que de explorar códigos culturales (Foster, 1985: 12).

Este posmodernismo resistente, como señala Foster, vuelve sobre la tradición para cuestionarla, tal como Campos viene haciendo en su teatro desde los últimos años de la dictadura. En cualquier caso, a partir de la posmodernidad artística la relación entre los creadores y la tradición sufriría una modificación sustancial, y esto se produce por igual en todas las artes ${ }^{14}$. Refiriéndose, en este caso, a la música, Gabriel Josipovici realiza la siguiente distinción entre dos

\footnotetext{
${ }^{14}$ Incluso quienes niegan toda validez al concepto de posmodernidad, como Andreas Huyssen, abogan por esta distinta relación con el pasado por parte de los creadores; así, el citado historiador de la cultura defiende una versión del modernismo «políticamente más modesta y estéticamente más abierta a las prácticas del pasado de lo que permitía la retórica utópica de la vanguardia histórica» (2011: 39).
} 
tipos de artistas que representan las actitudes moderna y posmoderna ante la tradición:

[...] mientras el estadounidense Cage se decantaba por el escepticismo de que había hecho gala Duchamp, los europeos [Stockhausen, Boulez, Nono, Ligeti y Kurtág] encontraron su fuente de inspiración en la música medieval y renacentista, al igual que en las músicas del lejano Oriente y del África central. En lugar de la ironía de inspiración budista adoptada por Cage, bebiendo en las obras de sus predecesores modernos, Schoenberg, Webern, Stravinski y Varèse, optaron por un nuevo idealismo, una nueva actitud para seguir adelante. [...] Mientras Cage y los suyos llegaban a la conclusión de que todas las tradiciones habían muerto, ellos comenzaron a fraguar nuevas tradiciones más integradoras, aun a sabiendas de que nunca mantendrían con ellas el mismo trato que a estas se les dispensara en tiempos de Bach o de Haydn (Josipovici, 2012: 162-163).

Las palabras con que Josipovici se refiere al ámbito de la música son perfectamente aplicables al resto de las artes. Si volvemos la mirada una vez más al terreno de la pintura, veremos que los transvanguardistas italianos no estaban solos en su aventura de recuperar los lenguajes del pasado. Por las mismas fechas, se dieron a conocer en diferentes galerías los neoexpresionistas alemanes, con cuadros «en los que aparecen imágenes reconocibles que hacen referencia a historias» (Maderuelo, 2012: 263). Tal como señala Maderuelo, de algún modo estas pinturas rompían «con el sentido positivista y evolutivo en el que se basaba el progresismo vanguardista» (2012: 264) y suponían la constatación de que la modernidad vanguardista había concluido, «ya que la modernidad se había convertido en academia, en estereotipo vacío de sí misma» ${ }^{15}$. En nuestro país, fueron dos pintores, Juan Navarro Baldeweg y Miquel Barceló, los representantes de este movimiento de euforia hacia la pintura que invadió Europa en los años setenta y ochenta (Maderuelo, 2012: 274). Ambos asimilaban modelos del pasado y recurrían a la cita, pero no tomada «de forma ni mimética ni literal, sino reinterpretada bajo una vigorosa técnica personal» (Maderuelo, 2012: 276). Son muchos los ejemplos que se podrían aportar como representativos de esta nueva actitud ante la tradición, tanto en las artes visuales como en la música, la arquitectura, la literatura o el teatro. Dentro del ámbito teatral, y ciñéndonos al caso español, baste con recordar que el discurso en la Real Academia de un autor tan próximo a la vanguardia como Francisco Nieva trató sobre la «Esencia y paradigma del género chico»: recuperación del pasado, mezcla de lo culto y lo popular, de tradición y vanguardia estaban aquí presentes de forma paradigmática. El de Campos, pues, lejos de ser un caso aislado, se inscribe así en un

\footnotetext{
15 «Esos caminos, al menos para los artistas alemanes, no debían tener corsés ni tabúes, pasaban por recuperar la representación, la ilusión, la expresión y, cómo no, continuaban por la experimentación en el más genuino sentido de la vanguardia, como mostrarán, desde diferentes posiciones conceptuales, pintores como Sigmar Polke y Gerhard Richter» (Maderuelo, 2012: 264).
} 
contexto de recreación de los lenguajes del pasado que se dio en todas las artes con especial intensidad a partir de los ochenta, pero cuyas semillas, tanto teóricas como creativas, se sembraron en la década de los sesenta, tal como ha explicado Maderuelo ${ }^{16}$.

Y a semejanza de lo que sucede con otros artistas aquí citados, en su caso, la recuperación de la tradición se produce desde la crítica de la misma, desde la ironía, desde la distancia, tal como pudimos constatar al referirnos a 7000 gallinas y un camello, En un nicho amueblado o Triple salto mortal con pirueta. Pero tal vez el texto que mejor ejemplifique esta relación lúdica e irreverente con la tradición sea A ciegas (1995), cuyo subtítulo, Auto sacro de realismo inverosímil o de la irrealidad verosímil, nos anuncia de entrada el género de partida. En este particular auto sacramental, Campos nos presenta a unos dioses cansados, descontentos con su obra, hastiados de su propia condición divina. Tal como ha señalado Arthur Danto, lo que singulariza a los creadores de la posmodernidad es la particular reinterpretación que llevan a cabo de los lenguajes aprendidos, la forma en que se relacionan con esos lenguajes: aunque pueden apropiarse de las formas del pasado y emplearlas para sus propios fines expresivos, ya no es posible relacionarse con ellas del mismo modo en que originalmente lo hicieron los artistas del pasado (Danto: 270-271).

Por otra parte, la asunción de las estrategias vanguardistas como un eslabón más de la tradición, a la que hicimos referencia a propósito de la transvanguardia, es igualmente una de las características del arte posmoderno en su conjunto, tal como ha señalado Lipovetsky: «la tradición se convierte en fuente viva de inspiración al mismo nivel que lo nuevo, todo el arte moderno aparece como una tradición entre otras» (2010: 121). Si nos fijamos de nuevo en A ciegas, comprobamos cómo coexisten en esta obra la estructura del auto sacramental, diálogos y situaciones propios de la comedia y un espacio escénico propio de la vanguardia más audaz, pues como se dijo la puesta en escena transcurría en la más absoluta oscuridad, con los intérpretes desplazándose entre el público.

Además de integrar elementos presentes y pasados, el posmodernismo, tal como explica Lipovetsky, también integraría elementos pertenecientes a la cultura popular y a la cultura de masas: «[...] si el efecto del modernismo fue efectivamente el incluir continuamente nuevos temas, materiales y combinaciones, es decir desublimar o democratizar la esfera estética, el posmodernismo no hace más que dar un paso suplementario en esa dirección» (2010: 124). Abundando en ese componente «inclusivo» del arte posmoderno ${ }^{17}$, de nuevo

\footnotetext{
${ }^{16}$ Este autor afirma que a partir de los ochenta se inició «el tiempo de la recogida, de la madurez, donde se aprecian los frutos ya maduros de aquellas ideas y propuestas» (Maderuelo, 2012: 326).

${ }^{17}$ Citando a C. Jencks (Le langage de l'architecture post-moderne. Denoël, 1979: 7), Lipovetsky afirma que «Mientras que el modernismo es exclusivo, "el posmodernismo es 
en $A$ ciegas - aunque se podrían citar igualmente otras obras de su producción-, junto con los recursos de la tradición culta y de la vanguardia, encontramos elementos inspirados en series televisivas y películas consideradas como subcultura, como el hecho de que un hombre dé a luz o la aparición en escena de un extraterrestre; si bien dichos elementos, como en el auto sacramental, adquirirán finalmente una significación simbólica.

También en este punto resulta evidente la proximidad entre este «proceso de abertura» y «ampliación de fronteras» a los que alude Lipovetsky y el «nomadismo» al que se refería Bonito Oliva. Una actitud ante el arte que, en definitiva, no solo se refiere a los aspectos formales, a la permeabilidad en el uso de formas antiguas y nuevas, «altas» y «bajas», sino que igualmente está relacionado con el fin de las ideologías rígidas, con la flexibilidad a la hora de presentar una determinada visión del mundo ${ }^{18}$; citando de nuevo al pensador francés: «El posmodernismo es la tentativa de insuflar un nuevo dinamismo al arte suavizando y multiplicando sus reglas de funcionamiento, a imagen y semejanza de una sociedad flexible, opcional» (Lipovetsky, 2010: 123).

\section{CONCLUSIONES}

Hasta aquí hemos visto cómo el teatro de Campos, en su relación con la tradición que le precedió, asume plenamente algunos de los rasgos más significativos de lo que supuso la irrupción de la posmodernidad en el arte y el teatro occidentales. La constatación de este aspecto pone en cuestión, como se dijo al principio de este artículo, algunos de los tópicos más reiterados por parte de la historiografía teatral dominante, como es el hecho de situar el origen de la posmodernidad (o, en cualquier caso, el origen de la etapa en la que aún estamos inmersos) en los años 80. Así mismo, el análisis del teatro de Campos hasta aquí realizado pone en cuestión igualmente la idea de una ruptura más o menos ra-

\footnotetext{
inclusivo hasta el punto de integrar incluso el purismo de su adversario cuando la cosa parece justificada"». Apud Lipovetsky (2010: 121). Así mismo, Lipovetsky señala que «ya no se trata de crear un nuevo estilo, sino de integrar todos los estilos, incluidos los más modernos» (2010: 121).

${ }^{18}$ En efecto, para el filósofo francés, esta libertad a la hora de acercarse a diferentes lenguajes artísticos tiene su correspondencia en una visión del mundo abierta y flexible propia de la posmodernidad:

El posmodernismo no tiene por objeto ni la destrucción de las formas modernas ni el resurgimiento del pasado, sino la coexistencia pacífica de estilos, el descrispamiento de la oposición tradición-modernidad, el fin de la antinomia local-internacional, la desestabilización de los compromisos rígidos por la figuración o la abstracción, en resumen, el relajamiento del espacio artístico paralelamente a una sociedad en la que las ideologías duras ya no entran, donde las instituciones buscan la opción y la participación, donde papeles e identidades se confunden, donde el individuo es flotante y tolerante (Lipovetsky, 2010: 122-123).
} 
dical entre el teatro neovanguardista de los últimos años de la dictadura y la supuesta «vuelta al orden» que se produjo tras la llegada de la democracia: la obra de este autor, como hemos podido constatar, aúna elementos de uno y otro tipo sin que ello suponga conflicto alguno, dentro de una poética coherente y propia del momento histórico en que se inscribe.

Más allá de lo que suponga el estudio de este teatro en cuanto a cuestionamiento de esquemas historiográficos establecidos, su análisis revela que nos encontramos ante un conjunto de obras fuertemente vinculadas con el arte de su tiempo, a nivel nacional e internacional, y representativas de una época, la nuestra, en la que el fin de la idea de una verdad única y de las llamadas ideologías «duras» han dado lugar a un arte en el que predomina el carácter de juego sobre el afán de concienciar o de impartir cualquier tipo de «mensaje», y en la que los creadores retoman imágenes y estructuras del pasado para dotarlas de una nueva significación. Nos referimos, páginas atrás, a la radical diferencia que se establece entre el realismo de Campos y el de los dramaturgos del realismo social. Tal vez el punto en el que radique la principal de estas diferencias sea su distinta concepción de lo que es la propia realidad, o dicho en otros términos, en una forma de entender la verdad no como un orden estable y objetivo, al modo en que esta era concebida por los ideólogos marxistas (con los que de algún modo simpatizan los dramaturgos realistas en su conjunto) y por otros pensadores metafísicos de signo ideológico opuesto, sino, en línea con el pensamiento posmoderno, como «una cuestión de interpretación», de puesta en acción de paradigmas que no son objetivos, sino fruto de un consenso social (Vattimo, 2010: 19).

Creemos que esta visión de la realidad como consenso social, como conjunto de convenciones acordadas, no solo resulta esencial a la hora de comprender la visión del mundo reflejada en los textos de Jesús Campos, sino que guarda estrecha relación con el diálogo con la tradición al que venimos haciendo referencia, pues ya no se trataría de buscar un lenguaje radicalmente nuevo y que sea el único válido, desechando todos los anteriores (al modo vanguardista), sino de dialogar con unos y otros, en la medida en que los lenguajes escénicos pretéritos y presentes constituyen igualmente la convención compartida por creador y espectadores, y por tanto, el terreno de juego sobre el cual se establece el hecho teatral; pues solo a partir de esas convenciones compartidas se podrá alcanzar una verdadera comunicación (Campos García). En la medida en que el pasado y la tradición han pasado a considerarse como algo abierto e interpretable ${ }^{19}$, se encuentra la idea de la imposibilidad de una

\footnotetext{
${ }^{19}$ Para Gianni Vattimo, el pasado no es algo cerrado, sino más bien un horizonte abierto que las interpretaciones no agotan nunca (2010: 16). Citando, a su vez, a Heidegger, Vattimo defiende una forma de «asumir como horizonte de posibilidad la herencia de la tradición a la cual somos lanzados», entendiéndola no como algo que puede conocerse de forma «objetiva», sino como «un mensaje que debemos interpretar y transformar a conciencia» (2010: 15).
} 
ruptura radical con este pasado; ya no se trata ni de superarlo críticamente ni de aceptarlo y repetirlo de forma acrítica, sino de reconsiderarlo y deconstruirlo, que en definitiva es lo que Campos viene haciendo desde sus inicios con las formas heredadas de la tradición teatral.

No existe, por el momento, mucha bibliografía sobre las relaciones entre teatro y posmodernidad en España. Pese a la complejidad que sin duda reviste el tema, en la mayoría de las ocasiones, cuando ha sido abordado, lo ha sido desde una fuerte influencia del método generacional, trazando, como se dijo, líneas divisorias tan radicales como inexplicables, tratándose de procesos culturales; como si ya en los setenta no se percibieran claros indicios en sus obras de una nueva sensibilidad ante la tradición, de una permeabilidad ante las distintas formas — cultas y populares, antiguas y modernas-, y de una visión del mundo flexible y claramente enmarcada en el fenómeno de la posmodernidad. El caso de Campos evidencia, una vez más, las limitaciones del método generacional a la hora de acercarnos al teatro español contemporáneo y la necesidad de revisar críticamente la dramaturgia de este período desde nuevas perspectivas abiertas al análisis de lo sucedido con el resto de las artes y con el resto de países de Occidente.

\section{FUENTES PRIMARIAS}

Bonito Oliva, Achille (1979). «The italian Trans-Avantgarde», Flash Art International (oct.nov.), pp. 19-20.

Bonito Oliva, Achille (1982). «La transvanguardia es hoy la única vanguardia», El País, 13 de febrero.

Bonito Oliva, Achille (ed.) (1986). Italiana 1950-1956, Monografías Cimal International, 9.

Bilbatúa, Miguel (1974). «Riaza: entre el realismo y el posibilismo», Pipirijaina-Textos. 3, pp. 5-8.

Campos García, Jesús (1974). «El autor. Historia a bulto. Siglo tal antes de Cristo hasta nuestros días. O cómo decir lo que es ser autor. Prosa», Pipirijaina. 6-7, pp. 16-18.

Campos García, Jesús (2005a). «Cuaderno de bitácora de Nacimiento, pasión y muerte de... por ejemplo: tú» [en línea], en http://www.jesuscampos.com/cuadernos/Bitacora_nacimient.pdf [ref. de 07 abril 2015]

López Sancho, Lorenzo (1980). «Es mentira o las complejas formas dramáticas de la realidad», $A B C .24$ de diciembre.

Martín, María (2002). «Entrevista con Jesús Campos» [en línea], en: http://www.cervantesvirtual. com/obra-visor-din/entrevista-con-jesus-campos-0/html/ffaef 4 ce-82b1-11df-acc7002185ce6064_1.html\#I_1_ [ref. de 07 abril 2015]. Alicante: Biblioteca Virtual Miguel de Cervantes.

Monleón, José (1976a). «El Lope de Vega, una parábola política», Triunfo. 692, 1 de mayo.

Navarro Arisa, Juan José (1989). «"La transvanguardia soy yo”, dice el crítico Achille Bonito Oliva», El País. 15 de febrero. 


\section{BIBLIOGRAFÍA CITADA}

Barrajón Muñoz, Jesús María (2003). «Nieva, Arrabal y el teatro de vanguardia», en Javier Huerta Calvo, Historia del teatro español, II. Madrid: Gredos, pp. 2821-2853.

Campos García, Jesús (1997). En un nicho amueblado. Madrid, Visor.

Campos García, Jesús (2001). «Escribir sobre lo escrito», Las Puertas del Drama. 6, p. 3. Campos García, Jesús (2003). «Las reglas del juego», Las Puertas del Drama. 14, p. 3.

Campos García, Jesús (2004). «Cuaderno de bitácora de Matrimonio de un autor teatral con la Junta de Censura», Las Puertas del Drama. 19, pp. 27-30.

Campos García, Jesús (2005b). «Pasar revista», Las Puertas del Drama. 22 (Primavera), p. 3.

Campos García, Jesús (2009). «Cuaderno de bitácora», en 7.000 gallinas y un camello, Sevilla, Centro de Documentación de las Artes Escénicas de Andalucía.

Campos García, Jesús (2014). «El espacio significante. Desde mi experiencia como autor escénico», Don Galán. Revista de Investigación Teatral [en línea]. 4, en http://teatro.es/ contenidos/donGalan/donGalanNum4/pagina.php?vol=4\&doc=2_1 [ref. de 07/04/15].

Carrillo, Jesús (2011). «Recuerdos y desacuerdos. A propósito de las narraciones del arte español de los 60 y 70», en Sonsoles Espinós et al., De la revuelta a la posmodernidad (1962-1982). Madrid: Museo Nacional Centro de Arte Reina Sofía, pp. 51-75.

Cornago Bernal, Óscar (2000). La vanguardia teatral en España (1965-1975). Del ritual al juego. Madrid: Visor.

Cornago Bernal, Óscar (2006). «Alegoría y ritualidad como paradigmas teatrales: del auto sacramental a la escena contemporánea» [en línea], en http://artesescenicas.uclm.es/ archivos_subidos/textos/272/alegoria_ritualidad_cornago.pdf [ref. de 07/04/15]. Original publicado en Hispanic Review. 74, 1, pp. 19-29

Danto, Arthur C. (2010). Después del fin del arte. Madrid, Paidós.

Fernández Insuela, Antonio (2012). «Una mirada al transgresor teatro de Jesús Campos García», Estreno. Cuadernos del Teatro Español Contemporáneo. XXXVIII, 1, pp. $12-26$

Fernández Torres, Alberto (1999). «Los simbolistas (por llamarles de algún modo). Una generación que apenas quiso serlo», Las Puertas del Drama. 0, pp. 29-31.

Foster, Hal (ed.) (1985). La posmodernidad. Barcelona: Kairós.

Guasch, Anna (2000). El arte último del siglo XX. Del posminimalismo a lo multicultural. Madrid: Alianza Editorial.

Habermas, Jürgen (1985). «La modernidad, un proyecto incompleto», en Foster (ed.), La posmodernidad. Barcelona: Kairós, pp. 19-36.

Heras, Santiago de las (1972). «Con Jesús Campos (entrevista)», Primer Acto. 146-147, pp. 8-11.

Huyssen, Andreas (2002). Después de la gran división. Modernismo, Cultura de masas, posmodernismo. Argentina: Adriana Hidalgo.

Huyssen, Andreas (2011). Modernismo después de la Posmodernidad. Barcelona, Gedisa.

Jiménez, Marc (2010). La querella del arte contemporáneo. Madrid: Amorrortu.

Josipovici, Gabriel (2012). ¿Qué fue de la Modernidad? Madrid: Turner.

Lipovetsky, Gilles (2010). La era del vacío. Ensayos sobre el individualismo contemporáneo. Octava edición. Barcelona: Anagrama.

Maderuelo, Javier (2012). Sucinta historia del arte europeo contemporáneo. Santander: Ediciones La Bahía.

Monleón, José (coord.) (1976b). Cuatro autores críticos (José María Rodríguez Méndez, José Martín Recuerda, Francisco Nieva, Jesús Campos). Granada: Gabinete de Teatro de la Universidad.

Muñoz Cáliz, Berta (2005). El teatro crítico español durante el franquismo, visto por sus censores. Madrid: Fundación Universitaria Española. 
Muñoz Cáliz, Berta (2013). «La alegoría en la obra de Jesús Campos», Signa. Revista de la Asociación Española de Semiótica. 23, pp. 635-660.

Oliva, César (1989). El teatro desde 1936. Madrid: Alhambra.

Paco, Mariano de (1971-1972). «El drama rural en España», Anales de la Universidad de Murcia. F. y Letras. XXX, 1-2, pp. 141-170.

Pérez-Rasilla, Eduardo (2003). «El teatro desde 1975», en Javier Huerta Calvo (dir.), Historia del teatro español, II. Madrid: Gredos, pp. 2855-2883.

Ruiz Ramón, Francisco (1992). Historia del teatro español. Siglo XX. Segunda edición ampliada. Madrid: Cátedra. (Primera edición de 1975).

Santolaria, Cristina (1994). «Notas sobre la enseñanza de la escritura teatral en España», Teatro. Revista de Estudios Teatrales. 5, pp. 229-238.

Santolaria, Cristina (1997). «Introducción», en Jesús Campos, A ciegas. Murcia: Servicio de Publicaciones de la Universidad de Murcia. Colección Antología Teatral Española.

Serrano, Virtudes (2012). «Jesús Campos, el intrépido jinete del teatro español», Estreno. Cuadernos del Teatro Español Contemporáneo. XXXVIII, 1, pp. 55-68.

Vattimo, Gianni (2010). Adiós a la verdad. Barcelona: Gedisa.

Vilches de Frutos, M. ${ }^{a}$ Francisca (1999). «La generación simbolista en el teatro español contemporáneo», en Martha T. Halsey y Phyllis Zatlin, Entre actos: diálogos sobre teatro español entre siglos. Pennsylvania: Estreno, pp. 127-136.

Wellwarth, George E. (1972). Spanish underground drama. University Park: The Pennsylvania State University Press. Edición española: Teatro español underground. Alberto Miralles (prol. y notas); Carmen Hierro (trad.). Madrid: Villalar, 1978.

Fecha de recepción: 1 de julio de 2013.

Fecha de aceptación: 4 de febrero de 2014. 